\title{
A Cerâmica como Elemento Facilitador do Processo de Aprendizagem do Uso de Modelos Físicos como Ferramenta de Projeto
}

\author{
Cristiane Aun Bertoldi* \\ Faculdade de Arquitetura e Urbanismo da Universidade de São Paulo
}

* Autora para correspondência: craun@usp.br

\section{RESUMO}

Este trabalho trata da necessidade de construção e do uso de modelos físicos como ferramentas de projeto, perpassando por todas as suas fases de desenvolvimento, desde a geração de conceitos até a validação de protótipos. Aponta como estratégia para o processo de aprendizagem em design o estímulo para o desenvolvimento de um projeto de produto cerâmico, visando à possibilidade de se chegar à obtenção de protótipos, aproximando a atividade de projeto da realidade encontrada na produção fabril. Os produtos cerâmicos são simples, compostos por poucos elementos unidos durante a conformação. Eles são confeccionados por processos tradicionais e acessíveis e apresentam baixa complexidade tecnológica. Propor o uso de materiais cerâmicos possibilita que o aluno organize o pensamento projetivo em função do comportamento do material e dos processos de fabricação e passe a compreender suas implicações no desenho de produtos, auxiliando a tomada de decisões durante o desenvolvimento do projeto.

Palavras-chave: Modelos Físicos; Ensino de Projeto; Cerâmica; Protótipo.

\begin{abstract}
This work is intended to look at the need of the construction and the use of physical models as design tools, undergoing all the development phases, from the concept generation to the prototype validation. The paper points to the encouragement for the development of ceramic product design, aiming at the possibility of obtaining prototypes, bringing the project activity closer to the reality found in the industrial production, as a strategy for the learning process in design. The ceramic products are simple, composed of few elements joined during the conformation. They are made through traditional and accessible processes, presenting low technological complexity. Proposing the use of ceramic materials enables the student to organize the design thinking according to the behavior of the material and the manufacturing processes and to understand their implications in the design of the product, helping them to make decisions during the development of the project.
\end{abstract}

Keywords: Physical Models; Design Teaching; Ceramics; Prototype.

\section{Introdução}

Os cursos de Design apresentam em seu currículo disciplinas que abordam o uso e a construção de modelos físicos; ministradas nos primeiros anos, contemplam conhecimentos básicos necessários para as demais disciplinas de projeto de produto. Na Faculdade de Arquitetura e Urbanismo da Universidade de São Paulo (FAU-USP), tanto o curso de Arquitetura e Urbanismo, quanto o de Design oferecem disciplinas que tratam desse tema e são organizadas com a finalidade de fornecer ao aluno conhecimentos acerca de teorias e tipologias de modelos físicos aplicadas ao projeto de produto e de elementos que envolvem a prática de principais métodos de construção de modelos físicos e a necessidade de desenvolvimento de habilidades perceptivas e operacionais para sua execução. $\mathrm{O}$ modelo é entendido como parte das atividades de projeto, estando presente em diferentes etapas, cumprindo funções específicas. Em decorrência 
disso, os fundamentos teóricos ensinados são importantes para reforçar a compreensão de que modelos não servem apenas para a apresentação final de uma proposta de projeto.

Uma estratégia adotada para essas disciplinas é a proposição de um exercício de redesign de um produto; dependendo da complexidade do objeto, propõe-se a ampliação da linha ou a criação de um kit de produtos. Outra estratégia é o estímulo para a especificação de um produto em cerâmica, que pode ser tanto para o objeto que será redesenhado, como para aqueles que comporão o kit ou a família. Incentivar o desenvolvimento de projetos de produtos feitos em materiais como cerâmica auxilia o processo de aprendizagem em projeto, principalmente quando ocorre nos primeiros anos do curso, devido à facilidade de obtenção, de transformação e de conformação, além da baixa complexidade tecnológica desses produtos e dos baixos custos de aquisição.

$\mathrm{O}$ contato direto com o material especificado em projeto e a possibilidade de seu emprego na conformação do objeto concebido favorecem a percepção e a avaliação das suas qualidades e a compreensão de seu comportamento, condição propiciada pela vivência em tempo real e não pela simples coleta de dados técnicos sobre propriedades e desempenho. A tentativa de aproximação do projeto com o produto final por meio de protótipos oferece meios para que o aluno realize testes de desempenho e simulações de uso, além de fazer com que ele se defronte com as limitações reais do processo de fabricação e se aproxime da capacidade de verificação e de validação do projeto em todas as suas instâncias. Nesse sentido, tal estratégia pode ser considerada proveitosa para o processo de ensino e aprendizagem em design.

Os produtos cerâmicos confeccionados por processos tradicionais apresentam baixa complexidade tecnológica. São produtos simples, compostos por poucos elementos. As partes são unidas logo após a conformação, antes da queima (Figura 1). Alguns produtos possuem tampas feitas do mesmo material e que são montadas para exposição no ponto de venda ou quando são colocados em uso. Maior ênfase pode ser dada na compreensão da geometria das peças, no volume desejado, nos atributos estéticos, manifestados na forma tridimensional, no acabamento superficial, no uso de cores e nos recursos de decoração.
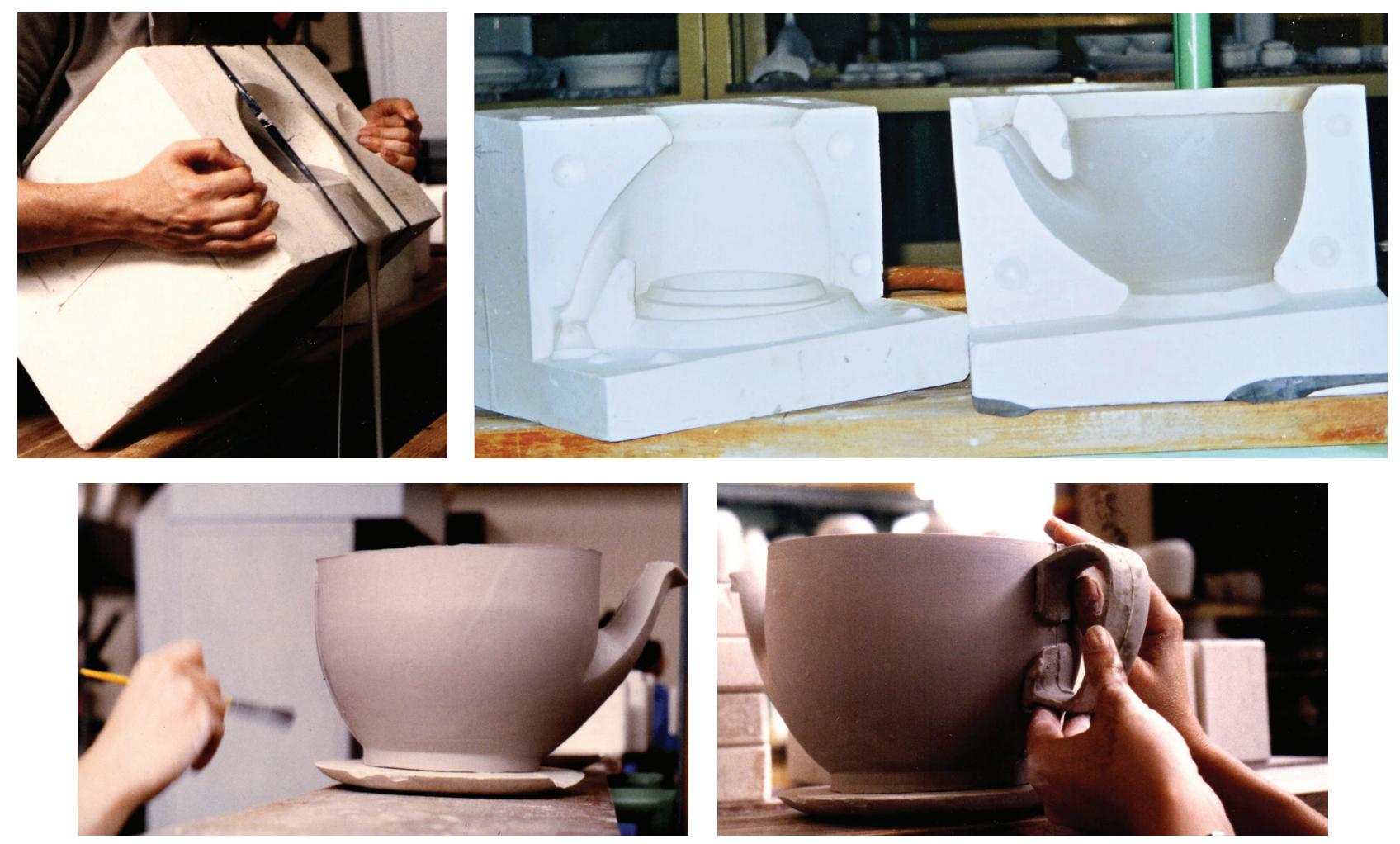

Figura 1 - Conformação por colagem em moldes de gesso e união de partes antes da queima. 
Os equipamentos necessários para a sua produção são, de certa maneira, bem acessíveis para as instituições de ensino superior. A conformação das peças por colagem e por tornearia exige a confecção de moldes de gesso, que são produzidos segundo conhecimentos e práticas bastante difundidos e acessíveis. Acredita-se que propor o uso de materiais cerâmicos possibilita que o aluno organize o pensamento projetivo em função do comportamento do material na fase de conformação, como é apontado por Quinn (2007, p. 8):

The type of clay you use affects the visual quality of the design. Each type of clay has its own qualities, and these should be taken into consideration during the design process. For example, earthenware is a stable clay, so it will be very faithful to your design after firing; alternatively porcelain contracts and shrinks a lot during the firing, so this needs to be taken into account in the original design ${ }^{1}$.

As qualidades superficiais do material são levadas em consideração, tais como a coloração do corpo, sua aspereza, e a densificação percebida, resultando na escolha de determinado tipo de massa cerâmica. A partir dessa escolha, é necessário o levantamento de especificações e de informações sobre a porcentagem de retração total da massa cerâmica, como o grau de sinterização do corpo obtido após a queima. Esses dados influenciarão no processo de execução de matrizes e moldes de gesso, compostos geralmente por várias partes ou tacelos para desenformar. A retração total de uma massa de cerâmica refere-se à retração de secagem e de queima, devendo ser compensada na confecção do modelo ampliado para a obtenção do molde de gesso. A confecção da peça com volume maior resultará naquela de tamanho desejado no final do processo produtivo. As massas podem apresentar retração total variando de $10 \%$ a $25 \%$, em virtude do grau de sinterização ou densificação. Esses valores são bastante elevados, e seu desconhecimento resultará em objetos sem controle dimensional.

A retração é passível de ser prevista como dado de projeto, mas a deformação só pode ser resolvida efetivamente na fase de testes com protótipos. Massas com alta porcentagem de fase vítrea provocam deformação da peça; ou seja, formas em balanço e com espessura fina tendem a baixar ou abrir, conforme a Figura 2. Também a forma idealizada pode interferir no grau de deformação da peça, pois formatos abertos e lisos tendem a desabar ou apresentar maior deformação do que aqueles contendo vincos e até mesmo estrias e relevos, que atuam como elementos estruturais, garantindo a manutenção da forma (Figura 3) (AUN, 2000).

Todos esses conhecimentos são considerados durante o projeto. Os desenhos para produção

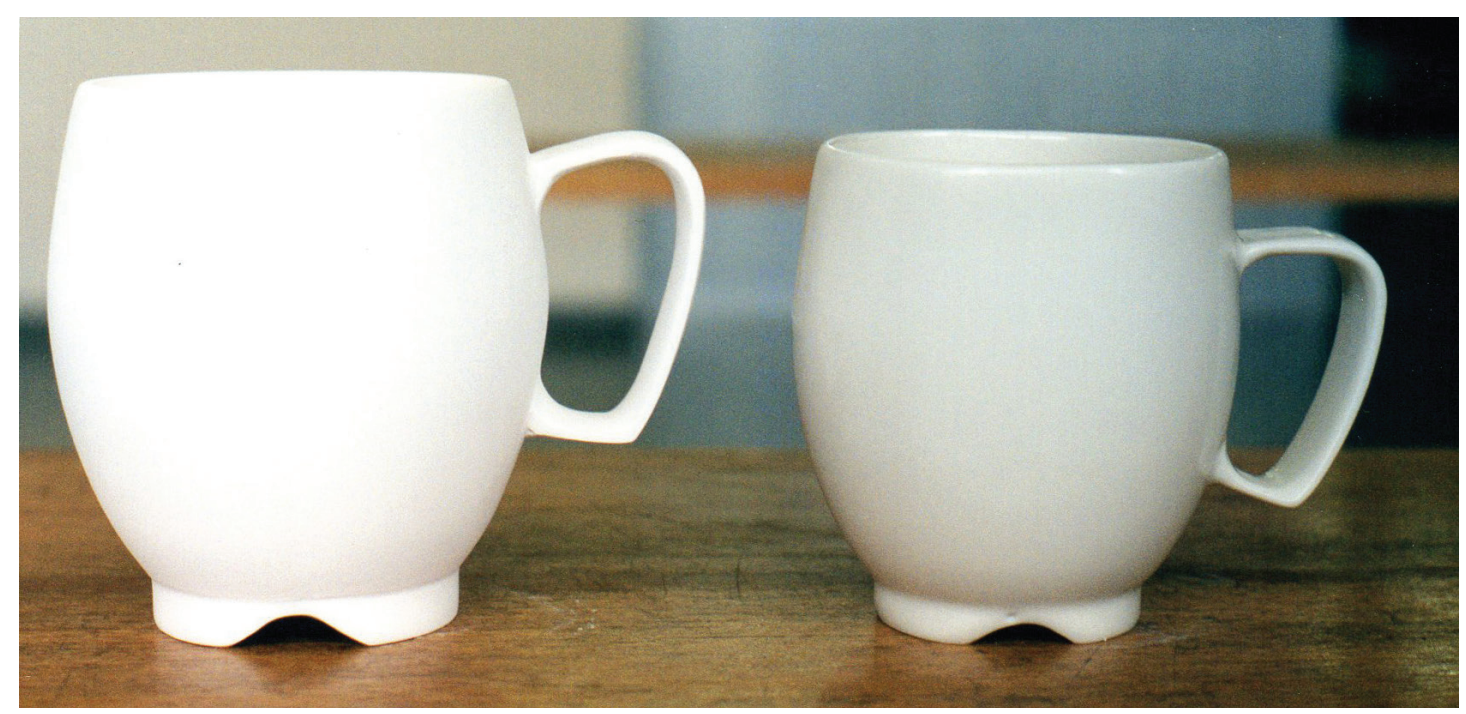

Figura 2 - Retração e deformação de peça com alto grau de fase vítrea: à esquerda, após a queima de biscoito a $1000^{\circ} \mathrm{C}$; e à direita, após a queima de vidrado a $1250^{\circ} \mathrm{C}$, com tamanho reduzido e alça levemente caída (AUN, 2007). 


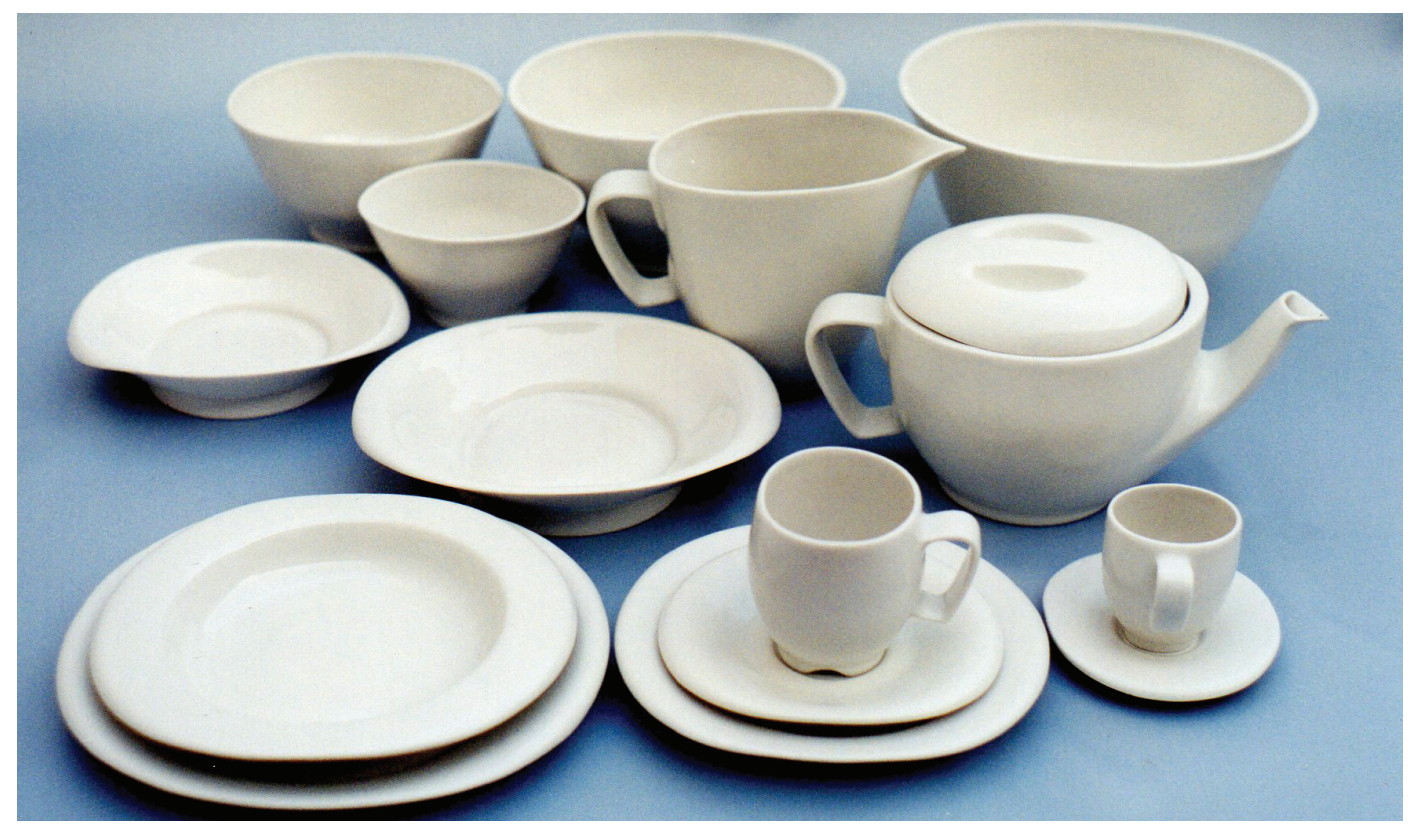

Figura 3 - Configurações abertas, com parede fina, das tigelas e travessas favorecem deformação, enquanto configurações fechadas das xícaras e bule do aparelho orbital sofrem menos deformações durante o processo de fabricação (AUN, 2000).

levam em conta a retração e a possível deformação da peça. As matrizes de gesso são realizadas a partir deles. Com os desenhos e as matrizes, é feito o planejamento para a construção do molde de gesso, conforme apresentado na Figura 4, em número de partes necessário para garantir a retirada da peça, evitando forçar a saída e provocar deformações que, mesmo quando corrigidas na peça crua, revelam o ocorrido após a queima, inutilizando-a (CHAVARRIA, 2006).

Obtidos os moldes de gesso, é confeccionada a primeira série de protótipo, empregando-se processos de conformação por colagem de barbotina e/ou por tornearia de massa cerâmica plástica. Conformadas, as peças são secas, é dado o acabamento, e são submetidas à queima do biscoito. A queima é realizada em forno elétrico, com atmosfera oxidante. Depois são feitas a vidração e a queima do vidrado, para se obterem a impermeabilização da peça, assim como as qualidades de desempenho referentes à dureza, à resistência mecânica e ao risco e as qualidades estéticas de coloração, textura, propriedades ópticas e superficiais (AUN, 2000).

Foram utilizados a massa de faiança feldspática preparada na forma de barbotina e o vidrado opaco e brilhante em suspensão fornecidos pela Escola Senai Mario Amato. Essa escola forma técnicos para a indústria cerâmica no Brasil e realiza prestação de serviços para a comunidade externa. Assim, na aquisição dos materiais, foram fornecidas informações completas sobre características, propriedades e recomendações de uso, evitando a realização de ensaios prévios no laboratório da faculdade.

Em alguns casos a primeira série de protótipos produzida resulta satisfatória, e o processo se encerra, mas, em outros, são necessários ajustes nos desenhos, matrizes e moldes para garantir a não deformação, a facilidade de reprodução e a manutenção do formato e volume especificados. A Figura 5 apresenta o processo de vidração por imersão (AUN, 2000).

Esse processo parece penoso e fatigante para os alunos, porém, ao fim do ciclo, passam a compreender as implicações dos materiais e processos produtivos no desenho de produtos, auxiliando a tomada de decisões durante o desenvolvimento do projeto. A compreensão do comportamento de uma categoria de material pode perfeitamente ser extrapolada e utilizada no projeto de outros produtos conformados na forma líquida ou plástica, como o vidro e o plástico.

A disciplina Modelos Físicos para o Desenho Industrial também conta com a proposição de um tema para motivação de reflexões quanto ao 


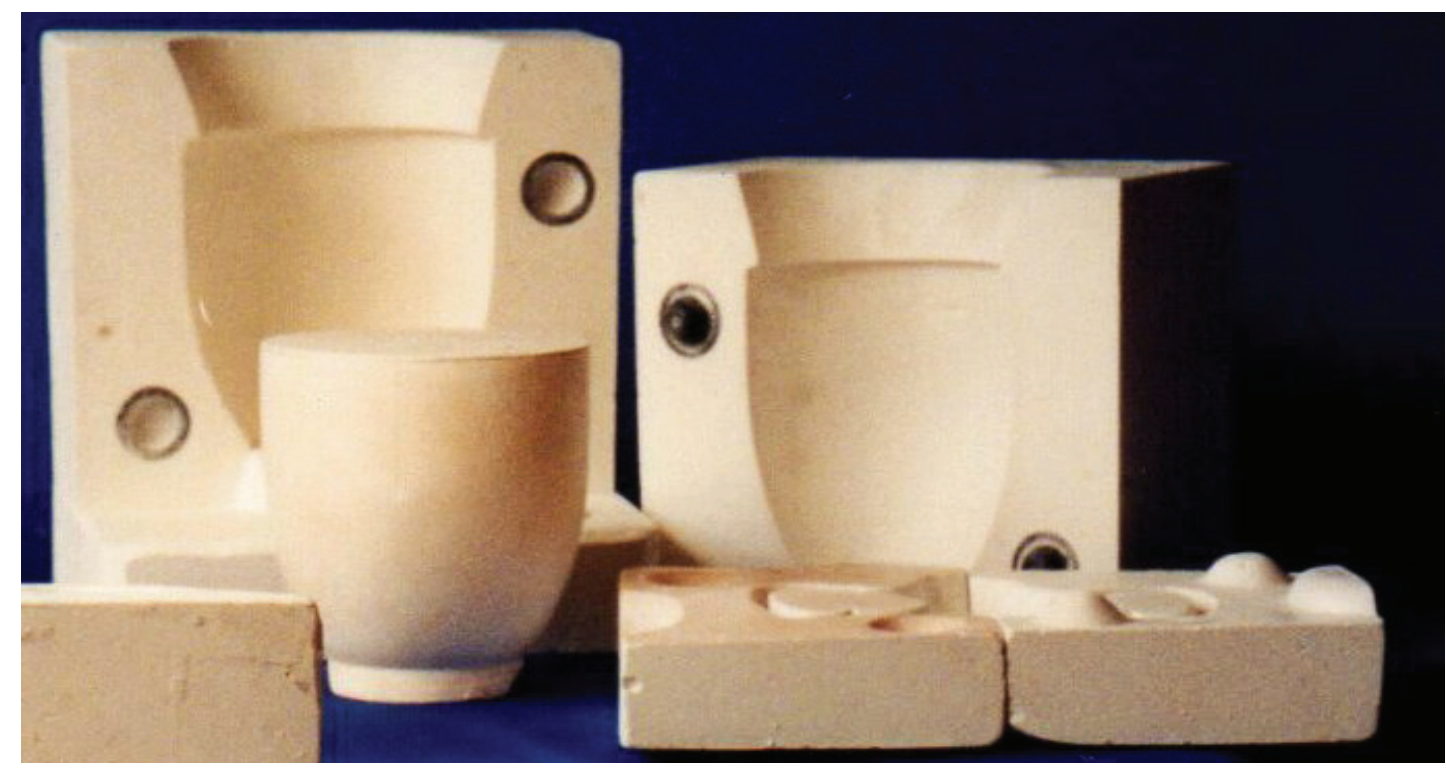

Figura 4 - Número de partes de um molde de gesso para a produção de peças de cerâmica. Para a xícara, são necessárias três partes, ou tacelos, uma na base e duas laterais; para a asa da xícara, apenas duas (AUN, 2000).

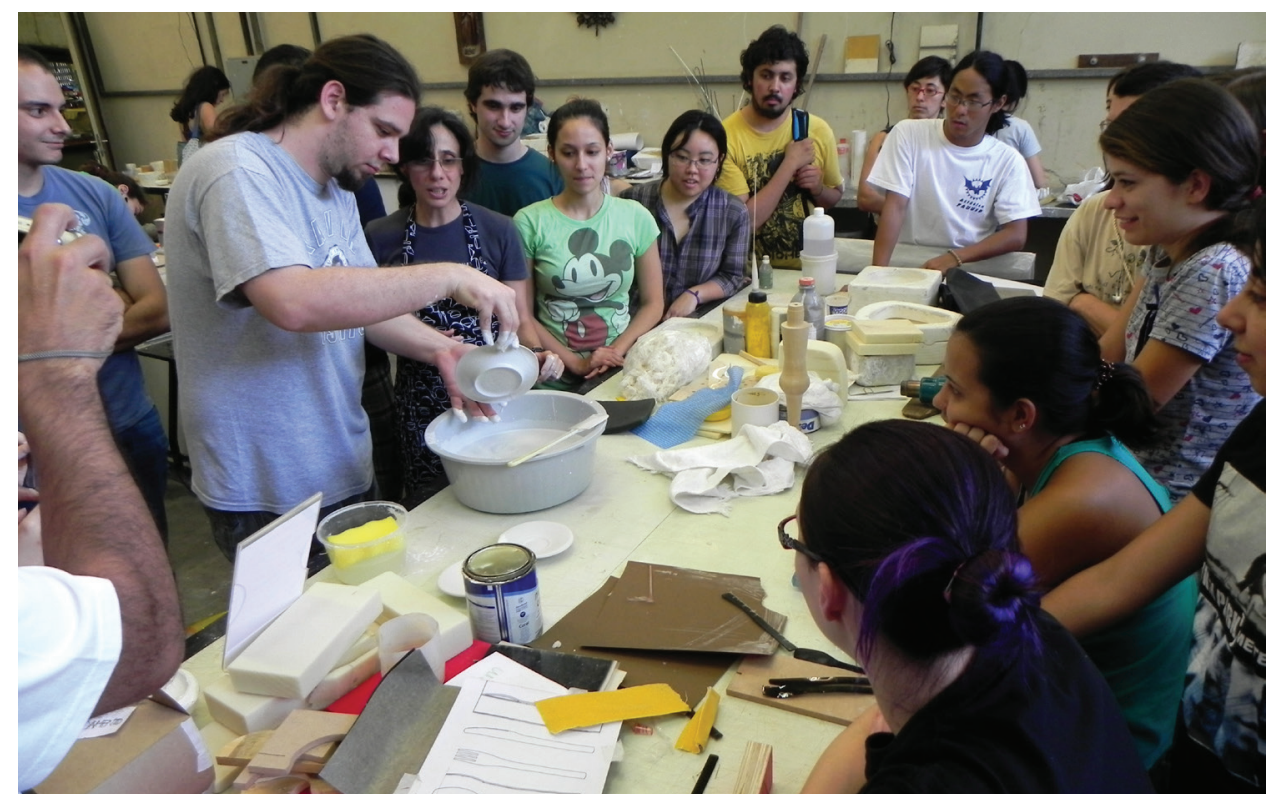

Figura 5 - Vidração de peças por imersão, empregando-se um vidrado branco brilhante para queima a $1250^{\circ} \mathrm{C}$.

uso de determinados produtos e sobre costumes e comportamentos sociais no desenrolar de atividades cotidianas. A temática trabalhada na disciplina envolveu o desenvolvimento de um kit de alimentação para viagem de uso individual, abordando questões sobre a necessidade de se comer fora de casa, o tempo exíguo disponível que desencoraja o preparo de alimentos no ambiente doméstico, a disponibilidade de produtos alimentícios para suprir essa falta e mudanças de hábitos e ritos relacionados ao comer. Esse tema proposto está alinhado à familiaridade dos alunos com o problema enunciado em razão das necessidades de estudo e/ou trabalho que eles vivenciam ou presenciam, favorecendo a análise e a crítica acerca de produtos similares que fazem, aumentando a capacidade de percepção de falhas ou demandas para a projeção de melhorias.

Na Figura 6, é possível verificar a solução encontrada para o problema proposto por um dos grupos de alunos da disciplina Modelos Físicos para Desenho Industrial.

Essa disciplina é semestral, com quatro horas semanais de aula, e exige horas a mais de trabalho em laboratório assistido pelos técnicos. Esse 


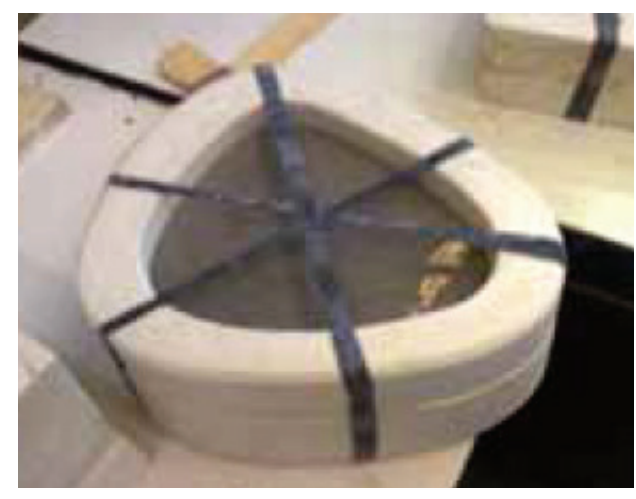

A

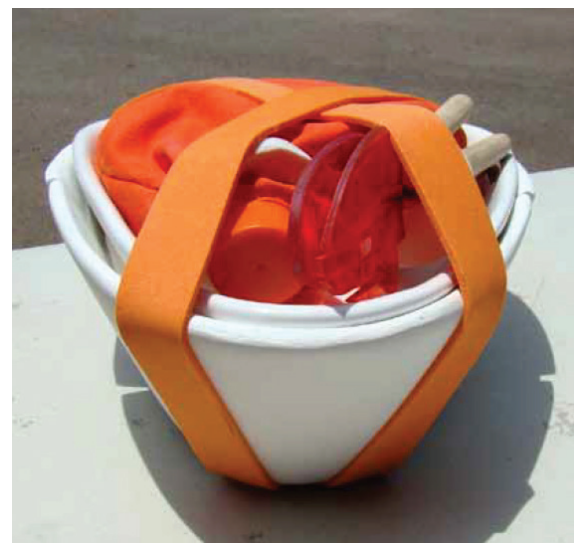

G

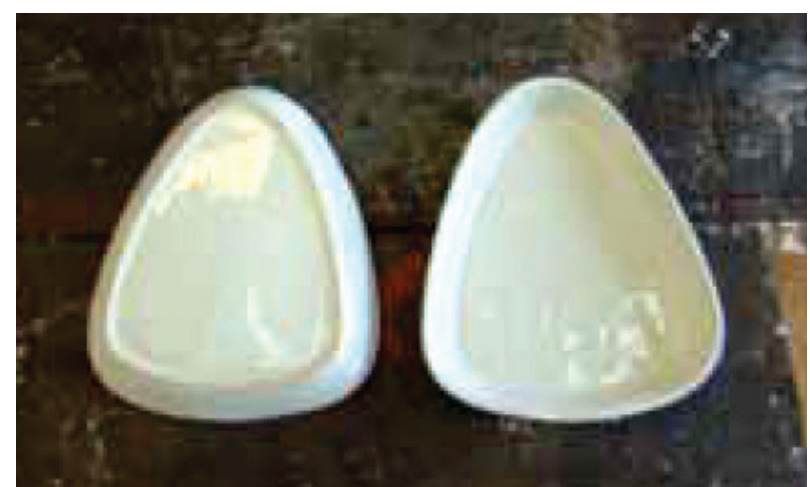

$\mathrm{B}$

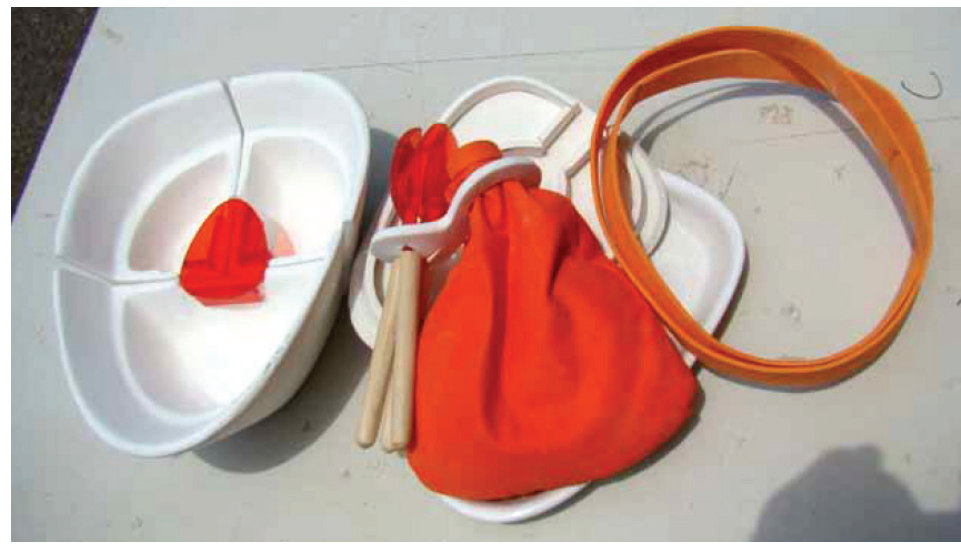

$\mathrm{D}$

Figura 6 - (A) Conformação de peça por colagem; (B) Duas séries de protótipos em cerâmica; (C) Kit de alimentação para viagem de uso individual - modelos de aparência e protótipo; (D) Apresentação das peças que compõem o kit. Alunos: José Eduardo Yáñez Vásquez, Maria Sueli S. S. Agnelli, Marina S. P. Bueno.

período é fundamental para garantir a finalização de modelos de aparência apropriadamente, com pintura, colagem de partes para construção, aplicação de adesivos com grafismos necessários ao produto e montagem do kit.

$\mathrm{Na}$ finalização do semestre, os alunos apresentaram em seminários as soluções desenvolvidas por cada grupo, havendo a possibilidade de debate sobre os resultados obtidos. Posteriormente à avaliação final, promoveu-se uma discussão com os alunos a respeito de dificuldades encontradas no processo, de falhas e problemas na dinâmica da disciplina percebidos por eles e de aspectos positivos ou relevantes quanto ao aprendizado dos conteúdos e das competências adquiridas por meio do método de ensino aplicado. Nesse processo de avaliação da disciplina verificou-se que, apesar da demanda de tempo e de dedicação, houve reconhecimento bastante favorável tanto da proposta, quanto dos resultados. Em debates realizados com alunos, percebeu-se que a estratégia de especificação de material cerâmico para o produto a ser projetado favorece a compreensão das implicações dos materiais e dos processos produtivos no seu desenho, e que tais conhecimentos adquiridos nessa experiência podem ser extrapolados e utilizados em projetos de produtos feitos com outros materiais.

\section{Nota}

1 O tipo de argila usado afeta a qualidade visual do design. Cada tipo de argila tem suas próprias qualidades, e isso deve ser levado em consideração durante o processo de design. Por exemplo, a massa cerâmica do tipo faiança é uma argila estável e, assim, será muito fiel ao seu projeto depois da queima; de modo alternativo, a porcelana encolhe e contrai-se muito durante a queima, o que faz com que seja necessário considerar tal fato na concepção do projeto original. 


\section{Referências Bibliográficas}

AUN, G R. Proposta de uma Metodologia de Projeto para Louça Utilitária de Uso Doméstico. Dissertação de Mestrado, Faculdade de Arquitetura e Urbanismo, Universidade de São Paulo, São Paulo, 2000.
CHAVARRIA, Joaquim. Moldes. 4 ed. Barcelona: Parramón, 2006 [Coleção Aula de Cerâmica].

QUINN, A. The Ceramics Design Course. Principles, Practices, Techniques. London: Thames \& Hudson, 2007.

Publicado em 30/06/2017. 